\title{
THE EFFECT OF SUBSTRATE ON SURVIVAL AND DEVELOPMENT OF TWO SPECIES OF DeSERT fleas (SiphONAPTERA: Pulicidae)
}

\author{
KRASNOV B.R.*, KHOKHLOVA I.S.**, FIELDEN L.F.*** \& BURDELOVA N.V.*
}

\begin{abstract}
Summary :
Fleas Xenopsylla conformis mycerini and Xenopsylla ramesis replace each other on the same rodent host (Meriones crassus) in two habitats that differ in substrate texture /sand and loess-like sediments, respectively). We hypothesized that the substrate is an important factor determining flea distribution and studied survival of larvae, pupae and newly emerged adults as well as the rate of pre-imaginal development of these flea species in sand and loess rearing medium (=substrate). Texture of rearing medium did not affect survival and development rate of eggs in either $X$. c. mycerini or $X$. ramesis. Larval survival and the rate of development were both affected by the factor of substrate. Survival of X. c. mycerini larvae was significantly higher in sand than in loess substrate, whereas survival of $X$. ramesis larvae did not differ in different substrates. Larvae of both species developed faster in sand substrate than in loess substrate. Maximal survival time of $X$. c. mycerini larvae that died before pupation did not depend on substrate, whereas $X$. ramesis larvae survived significantly longer in loess than in sand substrate. Most pupae of both species survived successfully on both substrates, but the duration of pupal stages in sand substrate was longer than that in loess substrate in both species. Newly emerged adults of both species survived similar time in both sand and loess substrate. Irrespective of substrate, adult $X$. c. mycerini survived for a shorter time than did adult $X$. ramesis. No between-sex within-species differences in survival time of newly emerged adults in sand versus loess substrate were found in $X$. c. mycerini. Survival time of males and females of $X$. ramesis differed in sand substrate but not in loess substrate.
\end{abstract}

KEY WORDS : Xenopsylla conformis mycerini, Xenopsylla ramesis, rearing medium, substrate texture, survival, development

\section{INTRODUCTION}

F leas (Siphonaptera) alternate between periods of 1 occurring on the host body and periods occurring in the nest or burrow of the host. Thus, flea distribution is determined not only by the distribution

\footnotetext{
* Ramon Science Center, Jacob Blaustein Institute for Desert Research, Ben-Gurion University of the Negev, P.O.Box 194, Mizpe Ramon 80600, Israel.

** The Wyler Department of Dryland Agriculture, Jacob Blaustein Institute for Desert Research, Ben-Gurion University of the Negev, BeerSheva 84105, Israel.

*** Science Division, Truman State University, Kirksville, MO 63501, USA.

Correspondence: Boris R. Krasnov. Tel.: +972-8-6586337.

Fax: +972-8-6586369. E-mail: krasnov@bgumail.bgu.ac.il
}

Résumé : EFFETS DU SUBSTRAT SUR LA SURVIE ET LE DÉVELOPPEMENT DE Púces de RÉGIONS désertiques (Siphonaptera : Pulicidae)

Deux puces, Xenopsylla conformis mycerini et Xenophylla ramesis, se retrouvent l'une ou l'autre sur le même rongeur hôte (Meriones crassus) dans deux habitats qui diffèrent selon la texture du milieu (substrat: sable ou sédiment). Partant de l'hypothèse que la nature du substrat jove un rôle important dans la répartition de ces puces, nous avons étudié la survie de leurs larves, pupes et jeunes adultes, ainsi que le taux de développement pré-imaginal dans des milieux sablonneux ou sédimentaires (loess). La nature du substrat n'affecte pas la survie et le taux de développement des œuts, ni chez X. c. mycerini, ni chez X. ramesis. La survie des larves et leur développement sont tous les deux affectés par la qualité du substrat. La survie des lanes de X. c. mycerini est plus élevée dans le sable, alors que celle des larves de X. ramesis n'est pas influencée par le substrat. Les larves de chacune des deux espèces se développent plus rapidement dans le sable. La durée maximale de survie des larves de X. c. mycerini qui meurent avant le stade de pupe ne dépend pas du substrat, tandis que les larves de $X$. ramesis survivent plus longtemps en milieu sédimentaire qu'en milieu sablonneux. La plupart des pupes des deux espèces survivent dans les deux substrats, mais la durée des stades de pupe est plus longue dans le sable. Les jeunes adultes des deux espèces survivent un temps égal dans les deux milieux. Indépendamment de la nature du substrat, les adultes de X. c. mycerini vivent moins longtemps que ceux de $X$. ramesis. On n'observe pas de différences inter-sexe et intra-espèce des temps de survie des jeunes adultes de X. c. mycerini entre les deux substrats. Les temps de survie des mâles et des femelles de $X$. ramesis sont différents en milieu sablonneux, mais pas en milieu sédimentaire.

MOTS CLÉS : Xenopsylla conformis mycerini, Xenophylla ramesis, milieu substrat, survie, développement

of their hosts, but also by environmental factors. Furthermore, the flea life cycle also suggests strong environmental effects on their distribution because, in most cases, pre-imaginal flea development is entirely off-host and the survival of immature fleas is, thus, dependent on microclimatic conditions of host burrow or nest (e.g. Gerasimova, 1979; Zolotova \& Afanasieva, 1971). These microclimatic parameters are variable among host habitats.

We studied the distribution of fleas among different rodent hosts occupying different habitats in the Negev desert, Israel (Krasnov et al., 1997, 1998). It was found that the replacement of one species of flea, Xenopsylla conformis mycerini (Rothschild, 1904) with another Xenopsylla ramesis (Rothschild, 1904) occurred on the same rodent host Meriones crassus Sundevall, 1842 bet- 
ween two different habitats situated at the opposite sides of a steep precipitation gradient. Burrows of $M$. crassus in two habitats showed large differences in architecture (Shenbrot et al., in press). Burrows in "mesic" habitat were much more ventilated than those in "xeric" habitats resulting in between-habitat differences in burrow microclimate. Air temperature was lower and relative humidity was higher in burrows in "mesic" habitats than those in burrows in "xeric" habitats. Attempting to explain the pattern of distribution of the two species, we studied the effect of air temperature and relative humidity on survival and rate of development of pre-imaginal fleas as well as on resistance to starvation of adult insects (Krasnov et al., 2001a, b; 2002). We received contradictory results and concluded that paratopic habitat distribution of $X . c$. mycerini and $X$. ramesis cannot be explained by the differential response to different microclimatic conditions only. Other factors, such as between-habitat difference in soil texture, should also be involved.

The substrate in X. c. mycerini ("xeric") habitats is represented by sand, whereas that in $X$. ramesis ("mesic") habitats is represented by loess-like sediments (Krasnov et al., 1997; Shenbrot et al., in press). This difference presumably causes different soil moisture, which can influence both development time and survival of pre-imaginal fleas. Furthermore, a flea cocoon is covered by adhering particles of the nest substrate. Sand and loess particles differ in size and in physical properties. Consequently, we assumed that cocoon coverages built of sand or loess could differ in their abilities to absorb water, while active water vapour uptake has been shown to be important for cocooned fleas (Edney, 1947a; Rudolph \& Knulle, 1982).

We hypothesized that the substrate is an important factor determining flea distribution. To test this hypothesis we studied survival and development of $X . c$. mycerini and $X$. ramesis in sand and loess rearing medium. We predicted that the texture of substrate would affect the survival of pre-imaginal and newly emerged adults of X.c. mycerini and $X$. ramesis as well as the rate of pre-imaginal development, all else being equal. We also predicted that survival and development of $X . c$. mycerini would be higher in sand rearing medium than in loess rearing medium whereas the opposite would be true for $X$. ramesis.

\section{MATERIALS AND METHODS}

\section{FLEAS AND THEIR HOSTS}

$\mathrm{F}$ lea eggs were obtained from a laboratory colony of fleas started from field-collected specimens on $M$. crassus using the rearing procedures following by Silverman et al. (1981) and Metzger \& Rust (1997). Details of flea rearing procedures are described elsewhere (Krasnov et al., 2001a, b). The laboratory colony of $M$. crassus was established from animals captured in the field. Animals were bred and maintained at our laboratory for four years. Millet seeds and leaves of Atriplex halimus were fed ad libitum. Colonies of both fleas and rodents were maintained at $25^{\circ} \mathrm{C}$ and $75 \%$ RH with a photoperiod of 12:12 (Light:Dark) h.

\section{EXPERIMENTAL DESIGN}

Flea eggs were collected daily on pieces of filter paper placed in a pan under the rodent's nest box. Female fleas oviposited on these pieces of filter paper. Eggs on filter paper were then transferred into $20 \mathrm{ml}$ glass vials that contained a thin layer of clean sand or loess (from nine to 18 eggs per vial). Vials were covered with $5 \times 5 \mathrm{~cm}$ nylon screen held by a rubber band. After eggs hatched, the larvae were transferred into another vial with clean sand or loess and dry bovine blood (larvae nutrient medium). There were eight to 12 larvae per vial. After pupation the procedure was repeated as described above. There were four to five cocoons per vial. After the imago emerged, each flea was transferred into a new individual vial with a thin layer of sand or loess. Sand and loess material were taken from the natural localities inhabited by $X$. $c$. mycerini and $X$. ramesis, respectively.

All eggs, larvae, cocoons and newly emerged fleas were maintained at $25^{\circ} \mathrm{C}$ air temperature and $75 \% \mathrm{RH}$. Temperature was regulated in refrigerated incubators (FOC225E, Velp Scientifica srl, Milano, Italy). Humidity was regulated in $38 \times 23 \times 13 \mathrm{~cm}$ acrylic humidity chambers using saturated solution of potassium chloride as described by Winston \& Bates (1960). Temperature and humidity were monitored using Fisherbrand Traceable Humidity/Temperature Pen with Memory (Fisher Scientific International, NJ, USA). Thus, there were two experimental treatments (sand substrate and loess substrate) for each of three pre-imaginal stages and newly emerged adults of each species replicated 10 to 40 times.

\section{DATA RECORDING}

Vials were checked twice a day. Egg vials were checked until all larvae hatched or for 30 consecutive days. An egg was considered dead if no larva hatched during this period. The vials of larvae were checked until all larvae cocooned or were dead. Finally, vials that contained cocoons were checked either until all adults emerged from their cocoons or for 40 consecutive days. We shook the cocoon vials slightly during checking to stimulate flea emergence, because vibration has been reported to stimulate flea emergence 
from cocoons (Marshall, 1981). A pupa was considered dead if after $40 \mathrm{~d}$ no adult emerged. These cocoons were dissected and the stage at which the immature flea died (larva, pupa or pre-emerged imago) was identified. After death of each newly emerged imago, we identified its sex by examination of its genitalia under light microscopy. Identification of imago sex allowed us to identify whether each survivor to adulthood egg, larva or cocoon was male or female.

\section{STATISTICAL PROCESSING}

To adjust deviations from normality, we applied an arcsine transformation on the proportion of eggs, larvae or pupae that survived. Log-transformation was applied on the duration of maximal survival time of a larva. Survival was analyzed using 2-way ANOVAs with species and substrate (=rearing medium) as independent variables and the proportion of pre-imaginal fleas that survived as a dependent variable. Construction of additional cocoons by larvae in dependence on substrate was analyzed using multi-way cross-tabulation tables and Pearson $\chi^{2}$ tests for each 2-way table. The effect of the rearing medium on the maximal survival time of larvae and newly emerged adults was also tested using 2-way ANOVA with species and substrate as independent variables.

The duration of developmental time of each stage was log-transformed to adjust deviations from normality. Developmental time was analyzed using 2-way ANOVAs with species and substrate as independent variables. In addition, 2-way ANOVAs with substrate and sex as independent variables were applied for the analyses of sex differences in development time in dependence on substrate for each pre-imaginal stage in each flea species.

To test the effect of substrate on sex ratio of newly emerged adults we analyzed $2 \times 2$ contingency tables of emerged males and females using Yates corrected $\chi^{2}$ tests. We (a) searched for deviation of sex ratio of newly emerged adults from 1:1 and (b) compared this sex ratio within-species between-substrate. Tukey's Honest Significant Difference (HSD) tests for unequal samples were applied for all multiple comparisons. Data are presented as mean \pm S.E.

\section{RESULTS}

\section{SURVIVAL OF PRE-IMAGINAL FLEAS}

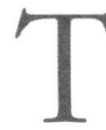
lexture of rearing medium did not affect survival of eggs in either flea species $(F=0.02 ; d f=1$, 23 and $F=0.16 ; d f=1,16$; respectively, $P>0.05$ for both). In addition, no significant interaction between species and substrate factors in their influence on egg survival was found as well $(F=0.08 ; d f=1$, 39; $P>0.05$ ). Survival of X. C. mycerini eggs averaged $76.5 \pm 3.2 \%$, whereas that of $X$. ramesis eggs averaged $78.6 \pm 3.7 \%$ (Tukey's HSD tests, $P>0.05$ ).

Larval survival was affected by substrate texture $(F=12.11 ; d f=1,136 ; P<0.05)$. Survival of X. c. mycerini larvae was significantly higher in sand substrate than in loess substrate, whereas survival of $X$. ramesis larvae did not differ significantly in different substrates (Tukey's HSD tests, $P<0.05$ and $P>0.2$, respectively) (Fig. 1). Maximal survival time of X. c. mycerini larvae that died before pupation did not depend on substrate texture and averaged $20.8 \pm 1.5$ days in sand and $21.6 \pm 1.3$ days in loess (Tukey's HSD test, $P>0.5$ ). In contrast, $X$. ramesis larvae survived significantly longer in loess than in sand $(25.9 \pm 1.7$ days versus $20.2 \pm 1.3$ days, respectively, Tukey's HSD test, $P<0.05$ ). In addition, maximal survival time did not differ significantly among X. c. mycerini larvae in sand substrate, $X . c$. mycerini larvae in loess substrate and $X$. ramesis larvae in sand substrate (Tukey's HSD test, $P>0.05$ ), whereas maximal survival time of $X$. ramesis larvae in loess substrate was significantly longer than in other 3 treatments (Tukey's HSD test, $P<0.05$ ).
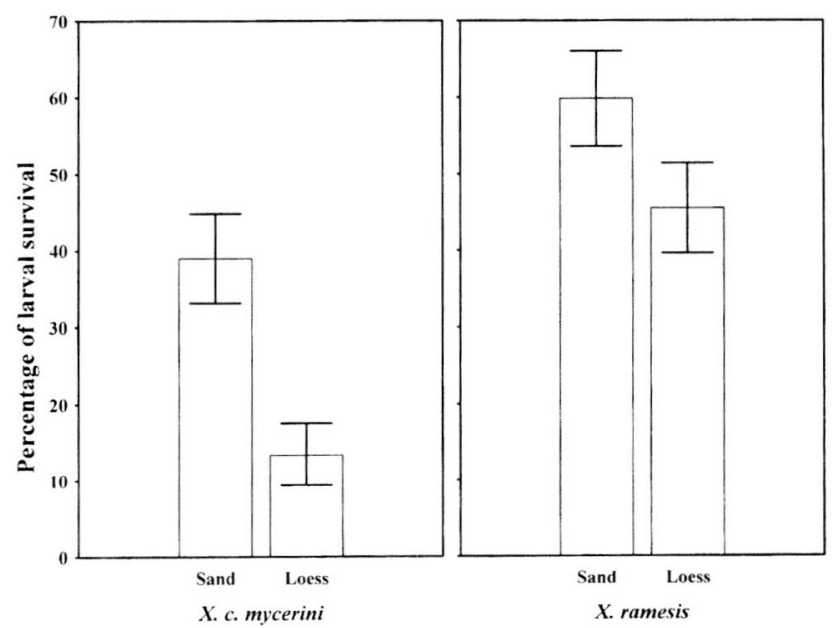

Fig. 1 - Mean ( \pm S.E.) percentage of larval survival of X. c. mycerini and $X$. ramesis in different substrates.

Some larvae left their cocoons soon after construction and constructed new cocoons. In general, larvae of both fleas build these additional cocoons with similar frequency (in $49.5 \%$ cases for X. c. mycerini and in $52.6 \%$ cases for $X$. ramesis, Pearson's $\chi^{2}=1.82 ; d f=1$; $P>0.05)$. However, the frequency of the construction of additional cocoons in sand versus loess substrate did not differ significantly in X. c. mycerini (in 23.8 versus $25.7 \%$ cases, respectively, Pearson's $\chi^{2}=0.03 ; d f=1$; $P>0.05$ ). In contrast, $X$. ramesis constructed additional cocoons in sand significantly more often that they did 
in loess (in 38.2 versus $14.4 \%$ cases, respectively, Pearson's $\left.\chi^{2}=8.03 ; d f=1 ; P>0.05\right)$. Nevertheless, the substrate had no effect on the amount of additional cocoons constructed by either species $(F=2.62 ; d f=1$, 42 for $X$. c. mycerini and $F=0.24 ; d f=1,48$ for $X$. ramesis, $P>0.05$ for both).

Most pupae of both species survived in both types of rearing medium. Only four of 263 experimental pupae died before emergence. All were X. c. mycerini (two in sand and two in loess) and died being in cocoons on a pre-pupal stage.

\section{DEVELOPMENT OF PRE-IMAGINAL FLEAS}

No general effect of substrate on the period of development from egg to larva was found in both flea species $(F=0.1, d f=1,832, P>0.05)$. Larvae of $X . c$. mycerini hatched from eggs slightly, albeit significantly, later than those of $X$. ramesis, all else being equal ( $F=6.2, d f=1,832, P<0.05$; Fig. 2$)$. Female eggs of $X$. c. mycerini developed to hatching faster than male eggs did $(5.40 \pm 0.06$ versus $5.62 \pm 0.07$ days, respectively, $F=7.7, d f=1,105, P<0.05$ ), whereas no significant between-sex difference in time to hatching was found in $X$. ramesis $(5.37 \pm 0.06$ days for females versus $5.33 \pm 0.06$ days for males, $F=0.4$, $d f=1,151, P>0.05)$. In addition, male eggs of $X . c$. mycerini developed faster in sand substrate than in loess substrate $(5.58 \pm 0.08$ versus $6.00 \pm 0.01$ days, respectively, Tukey's HSD test, $P<0.05$ ), whereas no effect of substrate was found for females of this species as well as for both sexes of $X$. ramesis (Tukey's HSD tests, $P>0.05$ ).
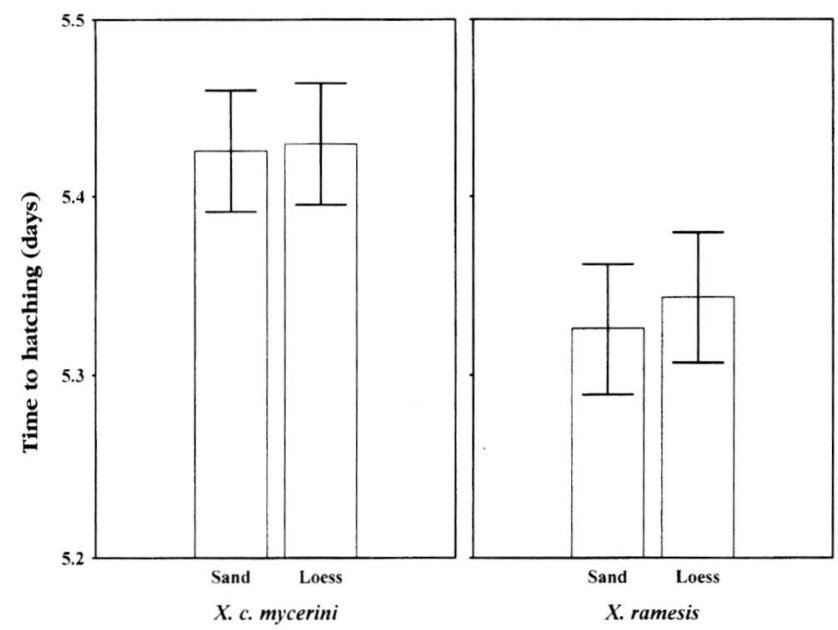

Fig. 2 - Mean ( \pm S.E.) development time (days) of eggs of X. c. mycerini and $X$. ramesis in different substrates.

Duration of time from larva hatching to pupation was affected by species and substrate factors $(F=17.87$; $d f=1,326$ and $F=18.16 ; d f=1,326$; respectively, $P<0.05$ for both). Larvae of both species developed faster in sand substrate than in loess substrate (Fig. 3). In addition, larvae of $X$. ramesis attained pupation for shorter time period than those of $X$. c. mycerini, all else being equal (Fig. 3). The rate of development did not differ significantly between female and male larvae of occurring in the same substrate $(X . c$. mycerini: $18.52 \pm 0.49$ days for females and 18.20 \pm 0.59 days for males; $F=0.5, d f=1,323 ; X$. ramesis: $17.18 \pm 0.38$ days for females and 17.24 \pm 0.48 days for males; $F=3.4$, $d f=1,455 ; P>0.05$ for both)

Substrate factor significantly affected the duration of pupal development $(F=10.02, d f=1,258 ; P<0.05)$, whereas the response to this factor did not differ between species $(F=0.11, d f=1,258 ; P>0.05)$. In addition, interaction between these two factors was nonsignificant $(F=0.06, d f=1,258 ; P>0.05)$. Duration of pupal stages in sand substrate was longer than that in loess substrate in both species (Fig. 4). In general, duration of female pupation was significantly shorter
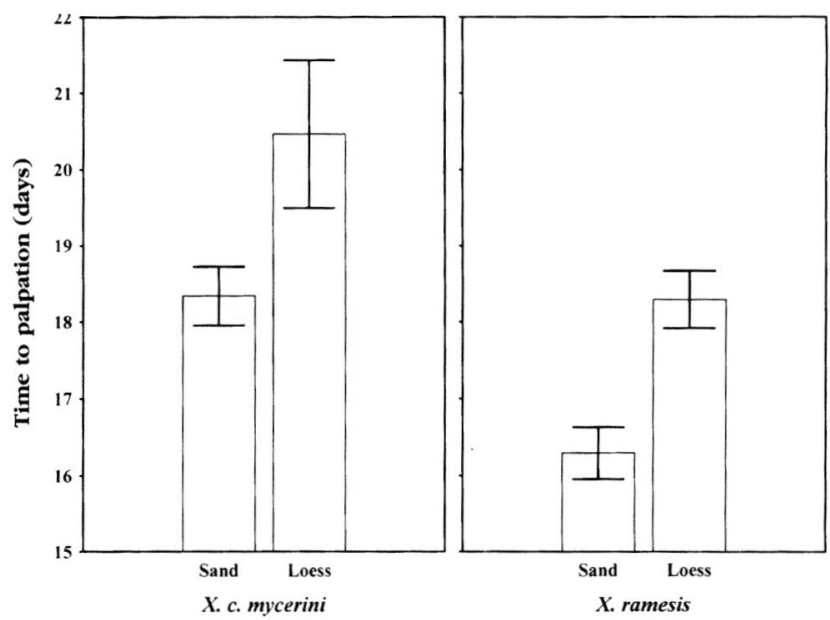

Fig. 3 - Mean ( \pm S.E.) development time (days) of larvae of $X$. $c$. mycerini and $X$. ramesis in different substrates.
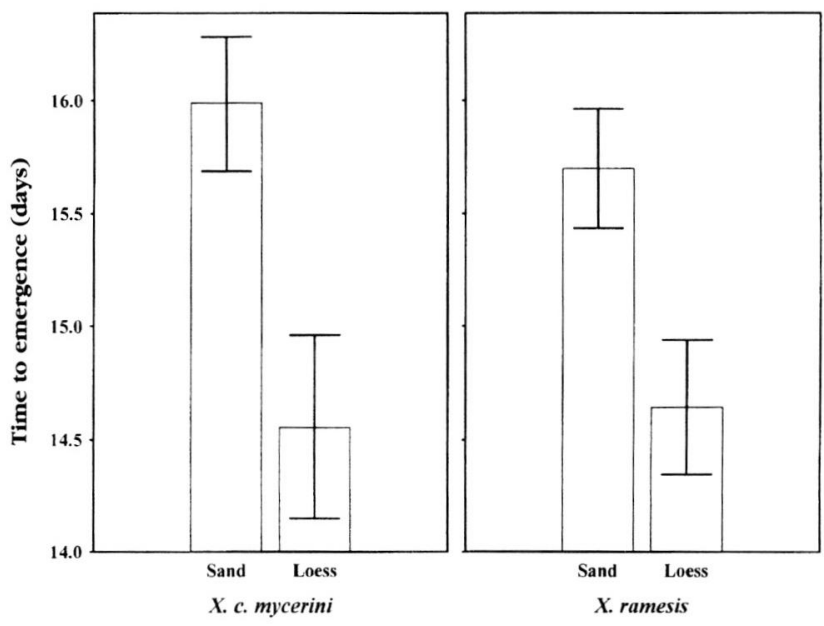

Fig. 4 - Mean ( \pm S.E.) pupation time (days) of X.c. mycerini and $X$. ramesis in different substrates. 
than that of male pupation in both species (X. C. mycerini: $14.77 \pm 0.27$ days for females and $17.45 \pm 0.44$ days for males; $F=7.38, d f=1,105 ; X$. ramesis: $13.75 \pm 0.16$ days for females and $17.54 \pm 0.24$ days for males; $F=159.31, d f=1,149 ; P<0.05$ for both).

Furthermore, pupation time of $X$. c. mycerini females did not depended on substrate texture (Tukey's HSD test, $P>0.05$ ), whereas the opposite was true for males of this species (Tukey's HSD test, $P<0.05$ ) with pupation time being shorter in loess substrate (Table I). In contrast, development rates of male and female pupae of $X$. ramesis were similar in the same substrate (Tukey's HSD tests, $\mathrm{P}>0.05$; Table I).

\begin{tabular}{lccc}
\hline Species & Sex & Substrate & $\begin{array}{c}\text { Duration of pupal } \\
\text { development (days) }\end{array}$ \\
\hline X.c. mycerini & Female & Sand & $14.9 \pm 0.3$ \\
& & Loess & $14.3 \pm 0.4$ \\
& Male & Sand & $17.7 \pm 0.5$ \\
& & Loess & $15.5 \pm 1.3$ \\
X. ramesis & Female & Sand & $14.0 \pm 0.2$ \\
& & Loess & $13.5 \pm 0.2$ \\
& Male & Sand & $17.4 \pm 0.3$ \\
& & Loess & $17.4 \pm 0.5$ \\
\hline
\end{tabular}

Table I - Mean ( \pm S.E.) duration of development of male and female pupae of X. c. mycerini and X. ramesis in different substrates.

\section{SURVIVAL TIME AND SEX RATIO OF NEWLY EMERGED ADULTS}

In general, newly emerged adults survived for a similar time in both sand and loess substrate. This was true for both species $(F=0.01, d f=1,256 ; P>0.05)$. However, irrespective of substrate, adult $X$. c. mycerini survived for a shorter time than did adult $X$. ramesis $(F=66.01, d f=1,256 ; P<0.05$; Fig. 5$)$. No between-sex within-species differences in survival time of newly emerged adults in sand versus loess substrate were found in X. c. mycerini ( $F=0.02$ for sex factor, $F=0.26$ for substrate factor, $F=0.16$ for interaction of these factors; $d f=1,103 ; P>0.05$ for both). In contrast, males and females of $X$. ramesis showed difference in survival rate in sand substrate but not in loess substrate $(F=6.43, d f=1,149 ; P<0.05$ for sex $\mathrm{x}$ substrate factor interaction) with females surviving less time than males (Tukey's HSD test, $P<0.05$; Fig. 5).

Sex ratio of newly emerged adult $X$. c. mycerini did not differ significantly either from 1:1 (Yates corrected $\chi^{2}=2.07$ in sand and $\chi^{2}=1.93$ in loess, $d f=1$, $P>0.05$ ) or between sand and loess substrate (Yates corrected $\chi^{2}=1.04, d f=1, P>0.05$ ). Sex ratio of newly emerged $X$. ramesis in sand substrate did not deviate significantly from 1:1 (Yates corrected $\chi^{2}=0.05, d f=1$, $P>0.05)$, whereas significant female bias occurred in loess substrate ( $71 \%$ on newly emerged fleas were females, Yates corrected $\chi^{2}=5.87, d f=1, P<0.05$ ).

\section{DISCUSSION}

\section{SUBSTRATE TEXTURE EFFECT}

The texture of substrate can determine its microclimatic conditions. For example, loess soils in all deserts absorb water best and their hydrothermic properties are similar to those of meadow soils (Korovin, 1961). This leads to increase of humidity that was shown to be very important in fleas (Sharif, 1949; Smith, 1951; Yinon et al. 1967; Krasnov et al., 2001a). Our predictions appeared to be true for larval survival of $X . c$. mycerini only. Larval survival of this species was significantly higher in sand substrate than in loess substrate, whereas it did not differ significantly between substrates in X. ramesis. Unlike our predictions, there was no effect of the substrate on the survival and development of eggs and survival of pupae and of newly emerged adults. In addition, larvae of both species developed faster in sand substrate that in loess substrate, whereas the opposite was the case for pupal development.

Eggs, pupae and newly emerged adults proved to be the less sensitive stages to the variation in rearing medium. As mentioned above, the important difference between sand and loess lies in their ability to absorb water and, thus, to affect the relative humidity of the immature flea environment. However, flea eggs are highly resistant to low humidity (Krasnov et al., 2001a) and, consequently, the variation in substrate texture had no evident effect on survival and rate of development.

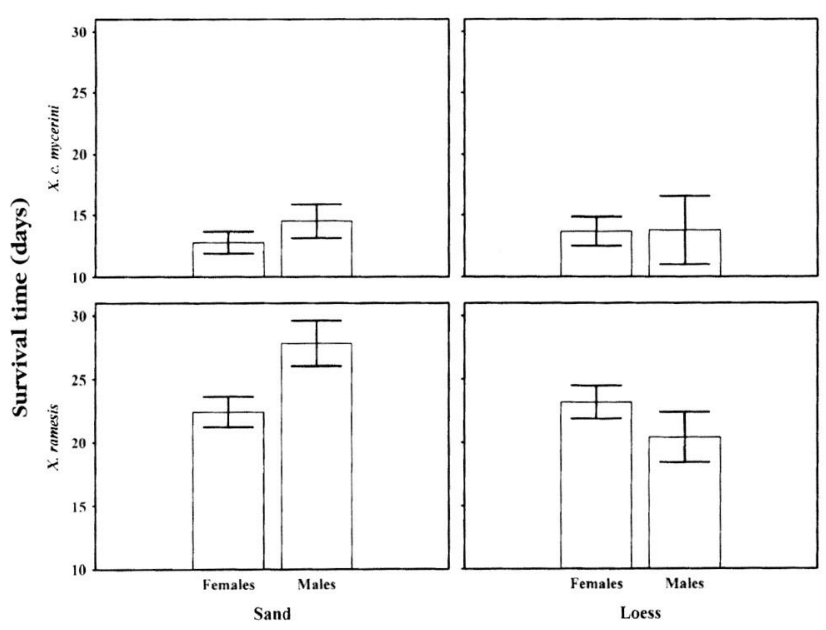

Fig. 5 - Mean ( \pm S.E.) survival time of newly emerged male and female $X$. c. mycerini and $X$. ramesis in different substrates. 
Flea pupae are enclosed within the protective microenvironment of a cocoon (Edney, 1947a) and, thus, are also resistant to low humidity, at least, in terms of survival (Krasnov et al., 2001a). However, pupae are unable to absorb atmospheric water via their rectal sac at low humidity (Edney, 1947b). This can explain the lower pupation time of both fleas in sand than in loess rearing medium.

The absence of the substrate texture effect on imago fleas may be due to the relative tolerance of adult X. C. mycerini and $X$. ramesis to dissication (Krasnov et al., 2002), although earlier results demonstrated the decline of flea survival with the humidity decrease due to high water loss, presumably because much time is spent with the spiracles open (Silverman et al., 1981; Cooke, 1999). This is especially true for newly emerged individuals (Krasnov et al., 2002). These individuals have lower mass specific metabolic rates (Fielden et al., 2001) and, consequently, lower oxygen requirements and water loss from the tracheal system (Bursell, 1974) than fed fleas.

The larval stage proved to be the most sensitive to the texture of the rearing medium. This sensitivity was manifested differently in the two fleas. In X.c. mycerini, survival of larvae was significantly higher in sand than in loess rearing medium, but maximal survival time of larvae that died before pupation did not depend on substrate texture. In X. ramesis, larvae survived similarly in different substrates, but maximal survival time in loess rearing medium was higher than that in sand rearing medium. Furthermore, survival of $X$. c. mycerini larvae in loess substrate was very low and attained only $13.4 \%$. These data support findings of Edney (1947b) that the longevity of larval Xenopsylla brasiliensis (Baker, 1904) and Xenopsylla cheopis (Rothschild, 1903) decreased drastically in the rearing medium with fine sand in comparison with that in the rearing medium with coarse sand. Nevertheless, in spite of sharp size differences of sand and loess particles, larvae of both species demonstrated an ability to use particles of both types to adhere to the cocoon for camouflage. However, higher frequency of the construction of additional cocoons by $X$. ramesis larvae in sand substrate in comparison with loess substrate suggests that this species is adapted to build cocoons using small substrate particles, whereas it leaves cocoons and constructs the new ones if only relatively large particles of substrate are available.

\section{BETWEEN-SEX DIFFERENCES}

In general, development of immature females in $X . c$. mycerini and $X$. ramesis was shorter than that of males on the egg and pupal stages. Previously, the shorter period of female development was reported only for pupal stages of Ctenocephalides felis (Bouché, 1835) (see Hudson \& Prince, 1958; Metzger \& Rust, 1997). Metzger \& Rust (1997) suggested that this prevents inbreeding of fleas from the same cohort. However, we mentioned earlier that the time difference between female and male development rate seems to be too small, albeit significant, for this explanation to be reasonable (Krasnov et al., 2001b). Instead, we suggested that immature males are more sensitive to environmental factors than immature females, at least in $X$. c. mycerini. Indeed, male eggs and pupae of this species developed at a different rate in different rearing mediums, whereas no effect was found for females. Previously, we found that male and female eggs and larvae of $X . c$. mycerini responded differently to air temperature and relative humidity (Krasnov et al., 2001b)

Another differential between-sex response to substrate texture was demonstrated by newly emerged adult $X$. ramesis. In this species, males and females survived differently in sand substrate but not in loess substrate with females being less tolerant than males. This suggests higher sensitivity of females to the substrate, unlike the pattern found in pre-imaginal X.c. mycerini, although adult female fleas have been shown to be less sensitive than males to fluctuations in air temperature and relative humidity (Krasnov et al., 2002).

\section{SUBSTRATE TEXTURE AND HABITAT DISTRIBUTION}

Contrary to our expectations, the effect of substrate on both survival and development rate of pre-imaginal and adult fleas did not appear to be especially strong. Furthermore, results of this study demonstrated that it is difficult to explain habitat distribution of X.c. mycerini and $X$. ramesis by between-habitat difference in the substrate alone. Nevertheless, higher survival of $X$. c. mycerini larvae in sand rearing medium can partly explain the absence of this species from "mesic loess" habitats, whereas longer survival time of $X$. ramesis larvae in loess rearing medium can partly explain its absence from "xeric sandy" habitats. Both these patterns suggest that between-habitat substrate differences can presumably affect habitat distribution of fleas, all else being equal. Taking into account our previous results (Krasnov et al., 2001a, 2001b, 2002), we propose that the factor of substrate texture interacts with other environmental factors (air temperature and humidity), and between-habitat distribution of the two fleas can be explained by an interaction of all three factors. Thus, the bottlenecks for the occurrence of $X$. ramesis in "xeric sand" habitats are (a) sensitivity of eggs, larvae and newly emerged imago to low relative humidity (Krasnov et al., 2001a, 2002) and (b) fast mortality of larvae in sand substrate (this study). Bottlenecks for the occurrence of X.c. mycerini in "mesic loess" habitats are (a) sensitivity of pupae to low tempera- 
ture (Krasnov et al., 2001b) and (b) low survival of larvae in loess substrate (this study).

Alternatively, the two flea species can occupy different habitats due to the result of interspecific competition with adult fleas competing for blood of a host (Day \& Benton, 1980) and/or larvae competing for space and food resources in the nest of a host (Marshall, 1981). Competitive outcome can also depend on microclimate conditions and/or larval food abundance because of difference in foraging efficiency between species. "Competition" and "environmental preferences" explanations of habitat distribution of $X . c$. mycerini and $X$. ramesis are not necessarily exclusive of each other. However, the "competition" hypothesis still requires experimental testing.

\section{ACKNOWLEDGEMENTS}

W e thank A. Degen (Ben-Gurion University of the Negev) and two anonymous referees for their helpful comments. This study was supported by the Israel Science Foundation (Grant no. 663/01-1 to B.R.K. and I.S.K.). Financial support was also received from the Israel Ministry of Science, the Israel Ministry of New Immigrant Absorption, and the Local Council of Mizpe Ramon. This is publication no. 133 of the Ramon Science Center.

\section{REFERENCES}

Bursell E. Environmental aspects - humidity, in: The Physiology of Insects, vol. 2. Rockstein M. (ed), Academic Press, New York, 1974, 44-84.

COOKE B.D. Notes on the life history of the rabbit flea Caenopsylla laptevi ibera Beaucournu \& Marquez, 1987 (Siphonaptera: Ceratophyllidae) in eastern Spain. Parasite, 1999, 6, 347-354.

DAY J.F. \& Benton A.H. Population dynamics and coevolution of adult siphonapteran parasites of the southern flying squirrel (Glaucomys volans volans). American Midland Naturalist, 1980, 103, 333-338.

EDNEY E.B. Laboratory studies on the bionomics of the rat fleas, Xenopsylla brasiliensis Baker and X. cheopis Rothsch. II. Water relations during the cocoon period. Bulletin of Entomological Research, 1947a, 38, 263-280.

EDNEY E.B. Laboratory studies on the bionomics of the rat fleas, Xenopsylla brasiliensis Baker and X. cheopis Roths. III. Further factors affecting adult longevity. Bulletin of Entomological Research, 1947b, 389-404.

Fielden L.J., Krasnov B.R. \& KhoKhlova I.S. Respiratory gas exchange in the flea Xenopsylla conformis (Siphonaptera: Pulicidae). Journal of Medical Entomology, 2001, 38, 735739.

Gerasimova N.G. [On the annual cycle of the flea Xenopsylla skrjabini. Zoologichskii Zhurnal, 1969, 48, 1410-1412.] (in Russian).

Hudson B.W. \& Prince F.M. A method for large-scale rearing of the cat flea, Ctenocephalides felis felis (Bouche). Bulletin of World Health Organization, 1958, 19, 11261129.

Korovin E.P. [Vegetation of Middle Asia and Southern Kazakhstan. Uzbekistan Academy of Science Press, Tashkent, USSR, 1961, 450 pp.] (in Russian).

Krasnov B.R., Shenbrot G.I., Medvedev S.G., VATSChenoK V.S. \& KHOKHLOva I.S. Host-habitat relation as an important determinant of spatial distribution of flea assemblages (Siphonaptera) on rodents in the Negev Desert. Parasito$\log y, 1997,114,159-173$.

Krasnov B.R., Shenbrot G.I., Medvedev S.G., KhoKhlova I.S. \& VATSCHENOK V.S. Habitat-dependence of a parasite-host relationship: flea assemblages in two gerbil species of the Negev Desert. Journal of Medical Entomology, 1998, 35, 303-313.

Krasnov B.R., Khokhlova I.S., Fielden L.J. \& Burdelova N.V. The effect of temperature and humidity on the survival of pre-imaginal stages of two flea species (Siphonaptera: Pulicidae). Journal of Medical Entomology, 2001a, 38, 629637.

Krasnov B.R., Khokhlova I.S., Fielden L.J. \& Burdelova N.V. Development rates of two Xenopsylla flea species in relation to air temperature and humidity. Medical and Veterinary Entomology, 2001b, 15, 249-258.

Krasnov B.R., Khokhlova I.S., Fielden L.J. \& Burdelov, N.V. Time to survival under starvation in two flea species (Siphonaptera: Pulicidae) at different air temperatures and relative humidities. Journal of Vector Ecology, 2002, 27, 112.

Marshall A.G. The Ecology of Ectoparasitic Insects. Academic Press, London, 1981, 459 pp.

Metzger M.E. \& Rust M.K. Effect of temperature on cat flea (Siphonaptera: Pulicidae) development and overwintering. Journal of Medical Entomology, 1997, 34, 173-178.

RudolPh D. \& KNulLE W. Novel uptake systems for atmospheric water vapor among insects. Journal of Experimental Zoology, 1982, 222, 321-333.

SHARIF M. Effects of constant temperature and humidity on the development of the larvae and the pupae of the three Indian species of Xenopsylla (Insecta: Siphonaptera). Philosophical Transactions of Royal Society of London B, 1949, 233, 581-633.

Shenbrot G.I., Krasnov B.R., Khokhlova I.S., Demidova T.V. \& FIELDEN L.F. Habitat-dependent differences in architecture and microclimate of the Sundevall's jird (Meriones crassus) burrows in the Negev Desert, Israel. Journal of Arid Environments, in press.

Silverman J., Rust M.K. \& ReIERson D.A. Influence of temperature and humidity on survival and development of the cat flea, Ctenocephalides felis (Siphonaptera: Pulicidae). Journal of Medical Entomology, 1981, 18, 78-83.

SMITH A. The effect of relative humidity on the activity of the tropical rat flea Xenopsylla cheopis (Roths.). Bulletin of Entomological Research, 1951, 42, 585-600. 
Winston P.W. \& BATES D.H. Saturated solutions for the control of humidity in biological research. Ecology, 1960, $41,232-237$.

Yinon U., Shulov A. \& Margalit Y. The hygroreaction of the larvae of the Oriental rat flea, Xenopsylla cheopis Rothsch. (Siphonaptera: Pulicidae). Parasitology, 1967, 57, 315-319.

Zolotova, S. I. \& Afanasieva, O. V. [On the biology of Ctenophthalmus dolichus Ioff, 1953 (Siphonaptera, Hystrichopsyllidae) from the great gerbil (Rhombomys opimus: Rodentia). Parazitologiya, 1971, 5, 364-368] (in Russian).

Reçu le 4 février 2002

Accepté le 2 avril 2002 